\title{
Earlier stage 1 palliation is associated with better clinical outcomes and lower costs for neonates with hypoplastic left heart syndrome
}

\author{
Brett R. Anderson, MD, MBA, ${ }^{\mathrm{a}}$ Adam J. Ciarleglio, PhD, ${ }^{\mathrm{b}}$ Arash Salavitabar, $\mathrm{MD},{ }^{\mathrm{c}}$ \\ Alejandro Torres, MD, ${ }^{a}$ and Emile A. Bacha, MD $^{\mathrm{d}}$
}

\begin{abstract}
Objectives: Our aim was to examine the effects of surgical timing on major morbidity, mortality, and total hospital reimbursement for late preterm and term infants with hypoplastic left heart syndrome (HLHS) undergoing stage 1 palliation within the first 2 weeks of life.
\end{abstract}

\begin{abstract}
Methods: We conducted a retrospective cohort study of infants aged $\geq 35$ weeks gestation, with HLHS, admitted to our institution at age $\leq 5$ days, between January 1, 2003, and January 1, 2013. Children with other cardiac abnormalities or other major comorbid conditions were excluded. Univariable and multivariable analyses were performed to determine the association between age at stage 1 palliation and major morbidity, mortality, and hospital reimbursement.
\end{abstract}

Results: One hundred thirty-four children met inclusion criteria. Mortality was $7.5 \%(n=10)$. Forty-three percent $(\mathrm{n}=58)$ experienced major morbidity. Median costs were $\$ 97,000$, in 2013 dollars (interquartile range, $\$ 72,000-\$ 151,000$ ). Median age at operation was 5 days (interquartile range, 3-7 days; full range, 1-14 days). All deaths occurred in patients operated on between 4 and 8 days of life. For every day later that surgery was performed, the odds of major morbidity rose by $15.7 \%(95 \%$ confidence interval, $2.5 \%-30.7 \% ; P=.018)$ and costs rose by $4.7 \%$ (95\% confidence interval, $0.9 \%-8.2 \% ; P<.014)$.

Conclusions: Delay of stage 1 palliation for neonates with HLHS is associated with increased morbidity and health care costs, even within the first 2 weeks of life. (J Thorac Cardiovasc Surg 2015;149:205-10)

See related commentary on pages 211-2.

\section{Supplemental material is available online.}

Despite significant improvements over the past 2 decades, morbidity and mortality for children with hypoplastic left heart syndrome (HLHS) undergoing stage 1 palliation (S1P) remain high. ${ }^{1,2} \mathrm{~A}$ handful of studies have reported improved morbidity and mortality with earlier age at operation, yet these studies have generally compared

\footnotetext{
From the Division of Pediatric Cardiology, ${ }^{\mathrm{a}}$ NewYork-Presbyterian/Morgan Stanley Children's Hospital, Columbia University Medical Center, New York, NY; Division of Biostatistics, ${ }^{b}$ Department of Child and Adolescent Psychiatry, New York University, New York, NY; Pediatrics Residency Program, ${ }^{\mathrm{c}}$ NewYork-Presbyterian/Morgan Stanley Children's Hospital, New York, NY; and Division of Cardiothoracic Surgery, ${ }^{\mathrm{d}}$ Columbia University College of Physicians and Surgeons, New York, NY.

Disclosures: Authors have nothing to disclose with regard to commercial support. Received for publication March 25, 2014; revisions received July 1, 2014; accepted for publication July 18, 2014; available ahead of print Sept 16, 2014.

Address for reprints: Emile A. Bacha, MD, NewYork-Presbyterian/Morgan Stanley

Children's Hospital, Columbia University Medical Center, 3959 Broadway, 2 N,

New York, NY 10032-3784 (E-mail: eb2709@cumc.columbia.edu). $0022-5223 / \$ 36.00$

Copyright (C) 2015 by The American Association for Thoracic Surgery http://dx.doi.org/10.1016/j.jtcvs.2014.07.094
}

standard care to late interventions (after 1-4 weeks). ${ }^{3-5}$ It is not known if timing of operation affects clinical outcomes for children with HLHS undergoing routine care. In addition, whereas HLHS is the most expensive birth defect managed in the United States, ${ }^{6,7}$ it is not known what effect surgical timing has on costs. We sought to determine the association between the timing of neonatal S1P and mortality, major morbidity, and total in-patient hospital costs, for late preterm and term infants with HLHS.

\section{METHODS \\ Patients}

We performed a retrospective cohort study, including all children aged $\geq 35$ weeks gestation with HLHS admitted to NewYork-Presbyterian/ Morgan Stanley Children's Hospital of Columbia University, at age $\leq 5$ days, between January 1, 2003, and January 1, 2013. HLHS was defined as a diminutive left ventricle in association with atresia or hypoplasia of the mitral and aortic valves. ${ }^{8}$ Children with aortic stenosis or atresia who had adequate left ventricles (such as double inlet left ventricle), as well as those with right-sided disease (such as pulmonary atresia with intact ventricular septum), adequate aortic outflow tracts (such as transposition of the great arteries with mitral atresia), atrioventricular or visceroatrial discordance, total anomalous pulmonary venous return, or atrioventricular septal defects were excluded, even if they underwent single-ventricle palliation. Children were further excluded if they had other major comorbid conditions, were discharged to home before admission to our institution, were taken to the operating room within the first 48 hours of life for a restrictive atrial septum, had positive blood cultures within the first 72 hours of life, or underwent an initial surgery other than the Norwood or Damus-Kaye-Stansel. This study was approved by the Columbia 


\section{Abbreviations and Acronyms \\ $\mathrm{CPB}=$ cardiopulmonary bypass \\ $\mathrm{DHCA}=$ deep hypothermic circulatory arrest \\ HLHS $=$ hypoplastic left heart syndrome \\ $\mathrm{S} 1 \mathrm{P}=$ stage 1 palliation}

University Medical Center Institutional Review Board, with waiver of informed consent.

\section{Predictor Variables}

The primary predictor of interest was age at operation (in days). Demographic variables included sex, birth weight (in kilograms), term gestation ( $\geq 37$ completed weeks), year of surgery (to reflect surgical era), insurance type (Medicaid or other), and day of the week of birth. Anatomic variables included anatomic subtype (eg, mitral atresia/aortic stenosis, mitral stenosis/aortic stenosis, mitral stenosis/aortic atresia, or mitral atresia/aortic atresia), partial anomalous pulmonary venous return, preoperative tricuspid regurgitation $(\geq$ moderate), preoperative right ventricular dysfunction ( $\geq$ moderate), and the presence of coronary fistulae. Other clinical variables included prenatal diagnosis, transfer from an outside hospital, preoperative diagnostic or therapeutic catheterization, preoperative mechanical ventilation, surgeon, shunt type, and cardiopulmonary bypass (CBP), crossclamp, and deep hypothermic circulatory arrest (DHCA) times. Day of birth was considered in 2 ways. First, it was included in the analysis as a set of 6 indicator variables, with Sunday serving as the reference. Then, it was dichotomized to indicate weekday or weekend (Saturday through Sunday) birth, after examining trends in the association with admission day and morbidity, mortality, and costs.

\section{Surgical Technique and Perioperative Management}

All patients were admitted preoperatively and managed postoperatively in the cardiac neonatal intensive care unit. All children received preoperative echocardiograms. The majority received prostaglandin E1. Patients underwent interventional catheterizations for restrictive atrial septum based on the clinical judgment of the inpatient cardiologists; no prespecified atrial gradient was used as a criterion.

All operations were performed by 1 of 4 surgeons at NewYorkPresbyterian/Morgan Stanley Children's Hospital, with an uneven distribution of cases (see Results). In the operating room, all patients underwent median sternotomy, hypothermic CBP, and aortic crossclamp with cold cardioplegic arrest and various amounts of DHCA. All children returned to the neonatal intensive care unit intubated and sedated, on inotropic support as determined by the anesthesiologist.

\section{Primary Outcomes}

We considered the primary outcomes of mortality, major morbidity, and costs. Mortality was defined as all-cause mortality before hospital discharge, not limited to 30 days. There was only 1 patient who underwent cardiac transplantation during initial hospitalization. This patient died before discharge and, therefore, was included in the analysis of mortality. Major morbidity was defined as cardiac arrest, extracorporeal membrane oxygenation, systemic infection, necrotizing enterocolitis, seizure, stroke on magnetic resonance imaging with clinical sequellae, postoperative catheterization before discharge, reoperation before discharge, readmission at $\leq 30$ days, or transplant. All patients who died experienced a morbidity before death, and therefore were included in the analyses of major morbidity. Costs were defined as total inpatient hospital reimbursement, based on individual billing records, to most accurately reflect societal costs. All costs were adjusted to January 2013 dollars using the Medical Consumer Price Index (http://www.bls.gov/cpi/\#tables). Costs did not include outpatient expenses or physician reimbursement.

\section{Statistical Analysis}

All statistical analyses were conducted in SPSS Statistics 21.0 (IBM-SPSS Inc, Armonk, NY) or Stata software, version 13 (StataCorp, College Station, Tex). Clinical and demographic variables were described with standard summary statistics. To assess the marginal associations between predictor variables and mortality or major morbidity, $\chi^{2}$ or Fisher exact tests were used for categorical variables, and $t$ tests or Wilcoxon rank sum tests were used for continuous variables. To assess the marginal associations between the predictor variables and adjusted costs, Wilcoxon rank sum or Kruskal-Wallis tests were used for categorical variables and Spearman correlations were used for continuous variables.

We hypothesized that the relationship between major morbidity or mortality and age at operation might not be linear. Locally weighted scatterplot smoothing (lowess) was used to determine an appropriate scale to use for age at operation in each model. It was determined that the association between the log odds of mortality and age at operation was best modeled by a quadratic function centered at 5.12 days, whereas the association between the log odds of morbidity and age at operation was best modeled by a linear function.

For major morbidity and mortality, logistic regression models were fit, using generalized estimating equations with exchangeable working correlation structure, to account for possible correlation between children operated on by the same surgeon. Because so few patients in our cohort died, rather than fitting a potentially large multivariable model, we constructed a simpler exploratory model that included only age at operation and age at operation squared. For costs, a linear mixed effects model was first fit to account for possible correlation between children operated on by the same surgeon. The variance component corresponding to the random intercept was estimated to be 0 , suggesting that a model without the random intercept was more appropriate. A linear regression model, therefore, was fit for costs, where age at operation was automatically included in the model. To account for the right-skewed nature of costs, costs were log-transformed before entering them into the models, and the top 5\% of costs were considered extreme outliers and excluded. Because some children with HLHS undergoing S1P die before discharge and because costs do not accrue postmortem, standard linear regression might incompletely capture the costs to society. Therefore, we also estimated censored regression models that censored the log of costs for patients who died. To examine the influence that small numbers of patients at the tail ends of the distribution for age might have on the results, sensitivity analyses were performed, rerunning multivariable models on the subset of the cohort operated on between the fifth and 95th percentiles for age at operation.

Final multivariable models were determined via a forward stepwise procedure, where age at operation was automatically included in the models. Variables with $P$ values $\leq .10$ in univariable analyses were evaluated together in multivariable analyses. Other variables were only retained in the final models if their $P$ values met the significance criterion or if their inclusion changed the magnitude of the coefficients for age at operation by $\geq 10 \%$.

\section{RESULTS}

One hundred thirty-four infants met our inclusion criteria. There was a slight male predominance $(63 \%$ boys). Mean birth weight was $3.10 \pm 0.47 \mathrm{~kg}$. The majority of children were born at $\geq 37$ weeks completed gestation $(71.3 \%)$. Fifty percent of children were covered by 
Medicaid insurance. Half of children had mitral atresia/ aortic atresia. Preoperatively, $6.0 \%$ of children had at least moderate tricuspid regurgitation, $3.7 \%$ had at least moderate right ventricular dysfunction, and $7.5 \%$ had suspected coronary fistulae. Two percent had partial anomalous pulmonary venous return. Most children were prenatally diagnosed $(82.1 \%)$, born at our institution $(72.4 \%)$, and born on a weekday $(89.6 \%)$, with no significant differences across time. The median age on admission was 0 days (interquartile range [IQR], 0-0). Preoperatively, $37.3 \%$ of children were mechanically ventilated, and $11.9 \%$ underwent cardiac catheterization. Two catheterizations were diagnostic (to delineate pulmonary venous anatomy); the rest were therapeutic ( 8 balloonings and 6 stentings of intra-atrial communications or decompressing veins.). Surgical volume was relatively constant over time. Forty percent of operations were performed by a single surgeon. Only this surgeon was at our institution for the duration of the study. The other $60 \%$ of surgeries were distributed among the 3 other surgeons, with those employed at our institution longer operating more. Right ventricle to pulmonary artery conduits were used in the majority of patients $(80.6 \%)$. Median CBP, crossclamp, and DHCA times were 141 (IQR, 129-166), 53 (IQR, 46-60), and 52 (IQR, 45-60) minutes, respectively (Table 1).

\section{Mortality}

In-hospital mortality was $7.5 \%(\mathrm{n}=10)$. All deaths occurred between days-of-life 4 and $8 ; 40$ operations $(30.0 \%)$ occurred before day-of-life 4 (39 on either day-of-life 2 or 3 ) with $0 \%$ mortality. Only 9 operations $(6.7 \%)$ occurred after day-of-life 8 (also with $0 \%$ mortality).

\section{Major Morbidity}

Forty-three percent $(\mathrm{n}=58)$ experienced major morbidity. The most frequent morbidities were readmission $(\mathrm{n}=25 ; 18.1 \%)$, systemic infection $(\mathrm{n}=17 ; 12.7 \%)$, reoperation $(\mathrm{n}=16 ; 11.9 \%)$, arrest $(\mathrm{n}=13 ; 9.7 \%)$, and postoperative catheterization $(\mathrm{n}=9 ; 6.7 \%)$. Other morbidities were rare (Table 1). In univariable analyses, major morbidity was significantly associated with age at operation, when age at operation was modeled as linear. For complete univariable results, see the Table E1.

\section{Costs}

Median hospital costs were $\$ 97,000$ in 2013 dollars (IQR, \$72,000-\$151,000), with a median length of stay of 22 days (IQR, 15-38 days). Median hospital costs per day were $\$ 4500$ (IQR, \$3700-\$5000). The median length of stay postoperatively was 17 days (IQR, 11-31 days) (Table 2). For complete univariable results, see the Table E1.
TABLE 1. Patient characteristics

\begin{tabular}{|c|c|}
\hline Characteristic & Result \\
\hline Male sex & $84(62.7)$ \\
\hline Birth weight $(\mathrm{kg})$ & $3.10 \pm 0.47$ \\
\hline Gestational age $<38 \mathrm{wk}$ & $25(18.7)$ \\
\hline Transferred from an outside hospital & $37(27.6)$ \\
\hline Age on admission (d) & $0(0-0)$ \\
\hline Age on admission if transferred (d) & $1(0-2)$ \\
\hline Age at operation (d) & $5.1(3.0-7.0)$ \\
\hline Insurance type, Medicaid & $67(50.0)$ \\
\hline Prenatal diagnosis & $110(82.1)$ \\
\hline \multicolumn{2}{|l|}{ Anatomy } \\
\hline Mitral atresia/aortic stenosis & $5(3.7)$ \\
\hline Mitral stenosis/aortic stenosis & $37(27.6)$ \\
\hline Mitral stenosis/aortic atresia & $29(21.6)$ \\
\hline Mitral atresia/aortic atresia & $63(47.0)$ \\
\hline Preoperative mechanical ventilation & $50(37.3)$ \\
\hline $\begin{array}{l}\text { Diagnostic catheterization performed } \\
\text { preoperatively }\end{array}$ & $2(1.5)$ \\
\hline $\begin{array}{l}\text { Therapeutic catheterization performed } \\
\text { preoperatively }\end{array}$ & $14(10.4)$ \\
\hline \multicolumn{2}{|l|}{ Shunt type } \\
\hline Aortopulmonary shunt & $26(19.4)$ \\
\hline $\begin{array}{l}\text { Right ventricle to pulmonary artery } \\
\text { conduit }\end{array}$ & $108(80.6)$ \\
\hline Bypass time (min) & $141(129-166)$ \\
\hline Cross-clamp time (min) & $53(46-60)$ \\
\hline $\begin{array}{l}\text { Deep hypothermic circulatory arrest } \\
\text { time (min) }\end{array}$ & $52(45-60)$ \\
\hline Partial anomalous pulmonary venous return & $3(2.2)$ \\
\hline Fistulae & $10(7.5)$ \\
\hline Right ventricular dysfunction, $\geq$ moderate & $5(3.7)$ \\
\hline Tricuspid regurgitation, $\geq$ moderate & $8(6.0)$ \\
\hline Mortality & $10(7.5)$ \\
\hline Major postoperative morbidity & $58(43.3)$ \\
\hline Arrest & $13(9.7)$ \\
\hline Extracorporeal membrane oxygenation & $1(0.7)$ \\
\hline Systemic infection & $17(12.7)$ \\
\hline Necrotizing enterocolitis & $3(2.2)$ \\
\hline Seizure & $4(3.0)$ \\
\hline $\begin{array}{l}\text { Stroke by magnetic resonance imaging } \\
\text { with associated clinical findings }\end{array}$ & $5(3.7)$ \\
\hline $\begin{array}{l}\text { Postoperative catheterization before } \\
\text { discharge }\end{array}$ & $9(6.7)$ \\
\hline Reoperation before discharge & $16(11.9)$ \\
\hline Readmission at $\leq 30 \mathrm{~d}$ & $24(17.9)$ \\
\hline Total adjusted hospital costs (US\$ 2013) & $\$ 97,000(\$ 72,000-\$ 151,000)$ \\
\hline $\begin{array}{l}\text { Total adjusted hospital costs per day } \\
\text { (US\$ 2013) }\end{array}$ & $\$ 4500(\$ 3700-\$ 5000)$ \\
\hline Total length-of-stay (d) & $22(10-38)$ \\
\hline Postoperative length of stay (d) & $17(11-31)$ \\
\hline
\end{tabular}

\section{Age at Operation}

The median age at operation was 5.1 days (IQR, 3.0-7.0 days). All children were operated on between days 1 and 14 . 
TABLE 2. The effects of age at operation on major morbidity

\begin{tabular}{lcr}
\hline & \multicolumn{2}{c}{ Major morbidity } \\
\cline { 2 - 3 } Parameter & Odds ratio $(\mathbf{9 5} \%$ confidence interval) & $\boldsymbol{P}$ value \\
\hline Age at operation & $1.16(1.03-1.31)$ & $.018^{*}$ \\
Crossclamp time & $1.03(1.02-1.05)$ & $<.001 *$ \\
\hline *Significant at $P \leq .05$ &
\end{tabular}

* Significant at $P \leq .05$

To assess the association between age at operation and major morbidity and total inpatient hospital costs, multivariable regressions were performed. It was found that, over the entire first 2 weeks of life, for every day later that surgery was performed, the odds of major morbidity increased by $15.7 \%$ (95\% confidence interval $[\mathrm{CI}], 2.5 \%-30.7 \% ; P=.018)$. Based on the linear regression model, for every day later that surgery was performed, costs rose by $4.1 \%(95 \% \mathrm{CI}, 0.4 \%-7.7 \% ; P=.032)$. Based on the censored model, for every day later that surgery was performed, costs rose by $4.7 \%$ (95\% CI, $0.9 \%-8.6 \%$; $P<.014)$. Final models are presented in Tables 2 and 3 and Figures 1 and 2. In sensitivity analyses, restricting our cohort to those operated on between the fifth and 95th percentiles for age had minimal effect on our results. In an exploratory mortality model, when modeled as quadratic, with age at operation and age at operation squared considered jointly, age was significantly associated with mortality $(P=.023$ and $<.001$, respectively). Because only 10 deaths occurred in our population, more robust multivariable models for mortality were not included.

\section{DISCUSSION}

In our retrospective cohort study, we found that later operation was significantly associated with increased morbidity and costs for late preterm and term infants with HLHS undergoing S1P even during the first 2 weeks of life. Morbidity and costs rose linearly with increasing age throughout the first and second weeks of life. These associations persisted, even after considering the effects of sex, birth weight, gestational age, year of operation,

TABLE 3. The effects of age at operation on adjusted total hospital costs

\begin{tabular}{llllll}
\hline & \multicolumn{4}{c}{ Adjusted costs } \\
\cline { 2 - 3 } \multicolumn{1}{c}{ Parameter } & \multicolumn{2}{c}{ Uncensored } & & \multicolumn{2}{c}{ Censored for death } \\
\cline { 2 - 3 } \cline { 5 - 6 } & $e^{\beta}(\mathbf{9 5} \% \mathbf{C I})$ & $\boldsymbol{P}$ value & & $e^{\beta} \mathbf{( 9 5 \%}$ CI) & $\boldsymbol{P}$ value \\
\hline Age at operation & $1.05(1.01-1.08)$ & $.020^{*}$ & & $1.05(1.01-1.09)$ & $.014^{*}$ \\
Age on admission & $0.91(0.84-0.99)$ & $.022^{*}$ & & $0.92(0.85-0.99)$ & $.027^{*}$ \\
Year of operation & $1.02(0.99-1.05)$ & .055 & & $1.03(1.00-1.06)$ & $.045^{*}$ \\
Catheterization $\dagger$ & $1.31(1.00-1.71)$ & .051 & & $1.45(1.09-1.91)$ & $.010^{*}$ \\
\hline All
\end{tabular}

All models were generated using the log of adjusted total hospital costs. Coefficients have been back transformed (to $e^{\beta}$ ) for ease of interpretation. $C I$, Confidence interval. *Significant at $P \leq .05$. †Preoperative therapeutic catheterization.

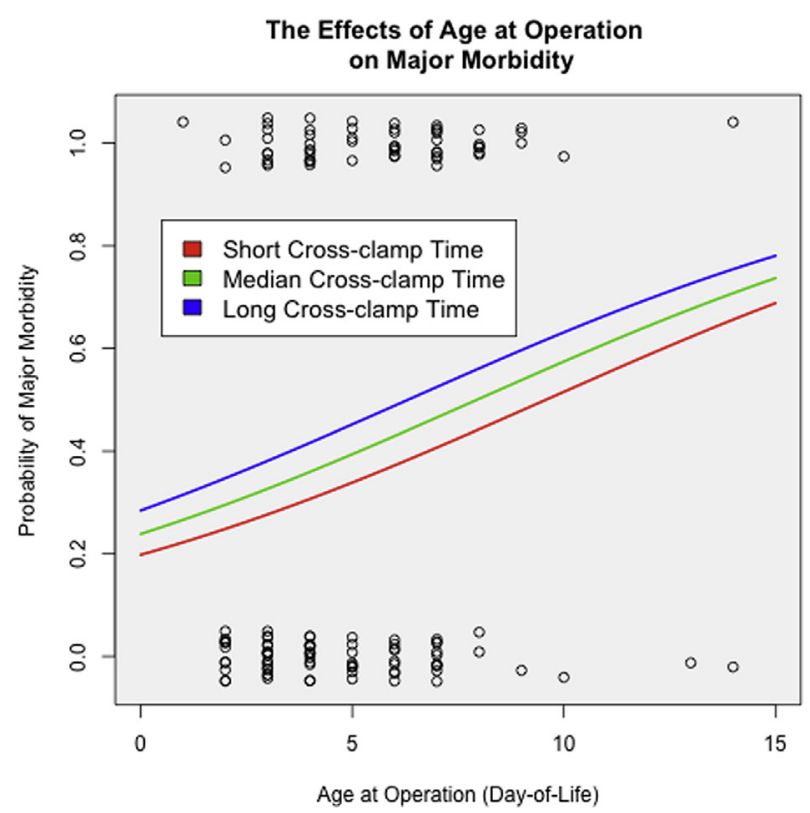

FIGURE 1. The effects of age at stage 1 palliation on major morbidity: Scatter plot depicting the probability of major morbidity as a function of age at operation. Representative curves are drawn to depict expected probabilities of major morbidity, given low (25th percentile) and high (75th percentile) crossclamp time, accounting for the effects of surgeon, using the results of the multivariable model.

age at admission, weekend birth, insurance type, prenatal diagnosis, anatomic morphology, preoperative mechanical ventilation, transcatheter intervention, surgeon, shunt type, CBP, crossclamp, and DHCA times, the presence of partial anomalous pulmonary venous return or coronary fistulae, and preoperative tricuspid regurgitation or right ventricular dysfunction, and after controlling for clustering by surgeon. Mortality appeared to be quadratically related to age at operation; there was no mortality observed in the $30 \%$ of children operated on before day-of-life 4 or in the $6.7 \%$ of children operated on after day-of-life 8 (vs $11.8 \%$ for those operated between ages 4 and 8 days). There were not sufficient data to evaluate these differences in multivariable analyses.

Other studies have generally shown worse clinical outcomes for children with HLHS operated on latechildren whose surgeries were delayed more than 1 to 4 weeks either because of late presentation, prematurity, low birth weight, multiorgan system failure, or other comorbidities. Most children with HLHS in the current era are operated on within the first 2 weeks of life $(100 \%$ of late preterm and term patients at our institution over the past 10 years). Limited data exists on the effects of surgical timing for these infants. In addition, for the most expensive birth defect managed in the United States, no one has looked at the effects of surgical timing on costs. In 2000, Mahle and colleagues ${ }^{3}$ showed that overall 
mortality was higher for children with HLHS undergoing S1P after day-of-life 14 than before. In 2008, Hehir and colleagues ${ }^{4}$ showed that interstage mortality was higher for infants with HLHS or other single ventricle variants operated on after day-of-life 7 than before. In 2011, Alsoufi and colleagues 5 showed that mortality was higher for children with HLHS or other single ventricle variants operated on between ages 14 and 21 days than for those operated on after age 21 days, but that pulmonary vasodilator and inotrope requirements were higher in the older cohort; their study excluded infants younger than age 14 days. Kumar and colleagues ${ }^{9}$ recently found that, for neonates with HLHS, age at operation, when considered as a linear variable, was not associated with poor outcomes (defined as mortality or length of intensive care unit stay $>75$ th percentile), but that, when considered as a dichotomous variable, older age at surgery (upper quartile, $\geq 8$ days) was predictive of prolonged mechanical ventilation and longer length of stay in the intensive care unit. In contrast, Karamlou and colleagues ${ }^{10}$ reported higher mortality at their institution for infants operated on before day-of-life 7 than for those operated on after.

We recently reported that, for late preterm and term infants with transposition of the great arteries, the odds of major morbidity declined as a function of age at operation between day-of-life 1 and day-of-life 3, but that, for every day that surgery was postponed beyond day-of-life 3, the odds of major morbidity rose by $47 \%$ (95\% CI, $23 \%-66 \% ; P<.001)$ and costs increased by $8 \%(95 \%$ CI, $5 \%-11 \% ; P<.001){ }^{11}{ }^{1} *$ This was consistent with our hypothesis that there might be an age below which maternal factors and/or persistent fetal physiology might lead to increased morbidity, but that, after a certain point, delay of operation might increase morbidity and costs as the result of prolonged exposure to medical interventions and increased lengths of hospital stays.

We hypothesized that there might be an analogous ideal age at operation for children with HLHS undergoing S1P, and that this might explain the results of Karamlou and colleagues. ${ }^{10}$ We used scatterplot smoothing methods to investigate the marginal association between age at operation and our outcomes of interest. Unlike that which we observed for children with transposition of the great

\footnotetext{
* The definition we used for major morbidity for children undergoing arterial switch operation included delayed sternal closure and diaphragmatic injury. For this analysis, these factors were not included in the definition of morbidity. This change was made because semielective delayed sternal closure after stage 1 palliation is frequent at our institution $(\mathrm{n}=57 ; 42.5 \%)$, and, given the relative gravity of the expected outcomes for children with hypoplastic left heart syndrome, diaphragmatic injury was not considered sufficiently severe to warrant inclusion. Secondary analyses were performed that included diaphragmatic injury in the definition of morbidity. Minimal difference was seen in our results. Under the broader definition, the incidence of major morbidity increased from $43.3 \%$ to $45.5 \%$, and age at operation was associated with a 1.13 times increase (vs 1.16 ) in the odds of major morbidity $(P=.038)$.
}

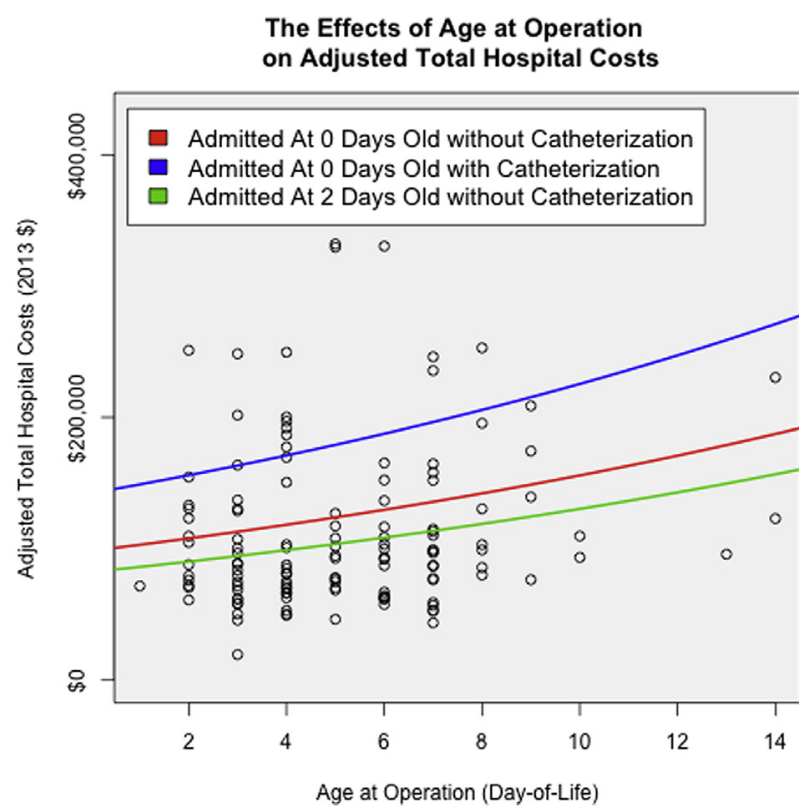

FIGURE 2. The effects of age at stage 1 palliation on adjusted total hospital costs: Scatter plot depicting the adjusted total hospital costs as a function of age at operation. Representative curves are drawn to depict expected costs in 2013, given low (0 days, 25th percentile) or high ( 2 days, 75th percentile if transferred from an outside hospital) age at admission, using the results of the multivariable model.

arteries, we found that the associations between age at operation and both the odds of major morbidity and costs for neonates with HLHS were best modeled as linear, increasing across all ages, with the lowest morbidity and costs observed in children operated on immediately after birth. We found that an infant, born at our institution during 2013, who did not require preoperative transcatheter intervention and who had a median crossclamp time, if operated on during day-of-life 3 would have an expected probability of morbidity of $33 \%$ and projected total hospital costs of $\$ 111,000$. In contrast, a similar child operated on during day-of-life 6 would have an expected probability of morbidity of $43 \%$ and projected total hospital costs of $\$ 127,000$ (Figures 1 and 2); any potential benefit to delayed operation derived from changing maternal and physiologic factors appears to be overshadowed in these children.

Although we did not have sufficient data to examine in depth the relationship between mortality and the potential predictors of interest, our exploratory model for the relationship between mortality and age at operation did, in fact, help to explain the findings of Karamlou and colleagues. ${ }^{10}$ Our analysis suggests that there is a quadratic relationship between the log-odds mortality and age at operation, with all of our mortality occurring between day-of-life 4 and day-of-life 8 . Karamlou and colleagues ${ }^{10}$ used a binary cutpoint at 1 week to define early versus late operation. The arbitrary use of set cutpoints, without 
considering the distribution of the data, can miss valuable information. Were we to use this same 7-day cutpoint, our mortality would also appear lower in older patients $(5.9 \%$ vs $8.7 \%$ ). This would fail to characterize the $0 \%$ mortality observed in the $30 \%$ of patients $(n=40)$ operated on before day-of-life 4. Larger studies, with more power, are needed to validate these trends in multivariable analyses.

Although our study focused on the effects of age at operation, it is worth mentioning that increased age on admission, in our study, was also associated with a decrease in costs. Because all children born at our institution were admitted on day-of-life 0 , these differences relate to children transferred to our institution early versus late, after controlling for the age at operation. The difference in costs is likely explained by the fact that our study does not include data on the costs incurred before admission. Of note, age at operation was moderately correlated with age on admission ( $\rho=0.32, P \leq .001)$, and it was the addition of age on admission to the multivariable model (negatively correlated with $\log$ costs and positively correlated with age at operation) that most dramatically affected the significance of age at operation, moving age at operation from not significant on univariable analyses to significant on multivariable analyses.

\section{Study Limitations}

There are a few notable limitations to our study. First, our study is retrospective, which limits our ability to imply causality. Thus, although we hypothesize that delay of S1P during the first week of life causes increased morbidity, mortality, and costs, there could be confounders leading to both delay of operation and increased morbidity, mortality, and costs. The most obvious potential confounder was the surgeon. Surgeon was not significantly associated either with any of the outcomes on univariable analyses or with age at operation $(P=.334)$. We accounted for potential clustering by surgeon by using generalized estimating equations and linear mixed effects modeling. Second, this study represents a single institution's experience and does not consider regional differences either in care or in reimbursement. Third, although there appeared to be no age after which either morbidity or costs improved with surgical delay, it is possible that low variance and small sample size inhibited our ability to detect a significant increase or decrease in morbidity or costs at the tails of our age distribution. Fourth, our follow-up only extended through hospital discharge and does not consider potential differences in long-term outcomes or outpatient costs. Fifth, physician costs were not included; this was thought to be acceptable, and is done routinely in cost analyses, because physician reimbursement typically constitutes $<5 \%$ to $10 \%$ of total inpatient reimbursement. Finally, as mentioned, costs were defined by hospital reimbursement. Although reimbursement costs reflect costs to society, they do not necessarily correlate with actual resource use.

\section{CONCLUSIONS}

In this retrospective study of late preterm and term infants with HLHS undergoing S1P, we found delay of operation during the first 2 weeks of life to be significantly associated with increased morbidity and total inpatient hospital costs. Assuming causal associations, these findings have several significant implications. First, our results suggest that S1P ought to be performed in late preterm and term infants as close to birth as possible. Second, we infer that, for infants undergoing scheduled deliveries, the date of delivery ought to be coordinated with surgeons' schedules to minimize wait times. Third, we conclude that, for infants born at institutions that do not perform S1P, transfer, or at least surgical scheduling, ought to be coordinated as early as possible. Larger, prospective studies are needed to confirm the ideal day of operation and the causal relationship of this association.

\section{References}

1. Jacobs JP, O'Brien SM, Pasquali SK, Jacobs ML, Lacour-Gayet FG, Tchervenkov CI, et al. Variation in outcomes for benchmark operations: an analysis of the Society of Thoracic Surgeons Congenital Heart Surgery Database. Ann Thorac Surg. 2011;92:2184-91; discussion 91-2.

2. Tabbutt S, Ghanayem N, Ravishankar C, Sleeper LA, Cooper DS, Frank DU, et al. Risk factors for hospital morbidity and mortality after the Norwood procedure: a report from the Pediatric Heart Network Single Ventricle Reconstruction trial. J Thorac Cardiovasc Surg. 2012;144:882-95.

3. Mahle WT, Spray TL, Wernovsky G, Gaynor JW, Clark BJ III. Survival after reconstructive surgery for hypoplastic left heart syndrome: a 15-year experience from a single institution. Circulation. 2000;102:III136-41.

4. Hehir DA, Dominguez TE, Ballweg JA, Ravishankar C, Marino BS, Bird GL, et al. Risk factors for interstage death after stage 1 reconstruction of hypoplastic left heart syndrome and variants. J Thorac Cardiovasc Surg. 2008;136:94-9. 9 e1-3

5. Alsoufi B, Manlhiot C, Al-Ahmadi M, Al-Halees Z, McCrindle BW, Mousa AY, et al. Older children at the time of the Norwood operation have ongoing mortality vulnerability that continues after cavopulmonary connection. J Thorac Cardiovasc Surg. 2011;142:142-7.e2.

6. Robbins JM, Bird TM, Tilford JM, Cleves MA, Hobbs CA. Hospital stays, hospital charges, and in-hospital deaths among infants with selected birth defects-United States, 2003. MMWR Morb Mortal Wkly Rep. 2007;56:25-9.

7. Keren R, Luan X, Localio R, Hall M, McLeod L, Dai D, et al. Prioritization of comparative effectiveness research topics in hospital pediatrics. Arch Pediatr Adolesc Med. 2012;166:1155-64.

8. Noonan JA, Nadas AS. The hypoplastic left heart syndrome: an analysis of 101 cases. Pediatr Clin North Am. 1958;5:1029-56.

9. Kumar TK, Charpie JR, Ohye RG, Hirsch-Romano JC, Donohue JE, Yu S, et al. Timing of neonatal cardiac surgery is not associated with perioperative outcomes. J Thorac Cardiovasc Surg. 2014;147:1573-9.

10. Karamlou T, Sexson K, Parrish A, Welke KF, McMullan DM, Permut L, et al. One size does not fit all: the influence of age at surgery on outcomes following Norwood operation. J Cardiothorac Surg. 2014;9:100.

11. Anderson BR, Ciarleglio AJ, Hayes DA, Vincent JA, Quaegebeur JM, Bacha EA. Earlier arterial switch operation improves outcomes and reduces costs for neonates with transposition of the great arteries. J Am Coll Cardiol. 2014;63: 481-7. 
TABLE E1. Predictors of morbidity, mortality, and costs in univariable analyses

\begin{tabular}{|c|c|c|c|}
\hline Predictor & $\begin{array}{c}\text { Major } \\
\text { morbidity }\end{array}$ & Mortality & $\begin{array}{c}\text { Adjusted } \\
\text { costs } \\
\end{array}$ \\
\hline $\operatorname{Sex}$ & .897 & .174 & .623 \\
\hline Birth weight & .812 & .369 & .327 \\
\hline Gestational age $<38 \mathrm{wk}$ & .713 & .395 & .148 \\
\hline Year of surgery & .423 & .115 & $.065^{*}$ \\
\hline Age on admission & .116 & .813 & $.004 *, \dagger$ \\
\hline Age at operation $\ddagger$ & $.014 *, \dagger$ & .175 & .174 \\
\hline Weekend birth & .290 & $.071 *$ & .839 \\
\hline Insurance type & .727 & $.049^{*}, \dagger$ & .671 \\
\hline Prenatal diagnosis & .860 & $.079 *$ & .144 \\
\hline Anatomy & .583 & .390 & .824 \\
\hline $\begin{array}{l}\text { Preoperative mechanical } \\
\text { ventilation }\end{array}$ & .817 & .743 & .195 \\
\hline $\begin{array}{l}\text { Therapeutic catheterization } \\
\text { performed }\end{array}$ & .269 & $.071^{*}$ & $.054^{*}$ \\
\hline Surgeon & .562 & .147 & 217 \\
\hline Shunt type & .226 & .407 & .570 \\
\hline Bypass time & .116 & $<.001^{*}, \dagger$ & .377 \\
\hline Crossclamp time & $.014^{*}, \dagger$ & $.009 *, \dagger$ & .546 \\
\hline $\begin{array}{l}\text { Partial anomalous pulmonary } \\
\text { venous return }\end{array}$ & .578 & .209 & .248 \\
\hline $\begin{array}{l}\text { Tricuspid regurgitation } \\
\text { preoperatively }\end{array}$ & .726 & 1.000 & .324 \\
\hline $\begin{array}{l}\text { Right ventricular dysfunction } \\
\text { preoperatively }\end{array}$ & 1.000 & $.045^{*}, \dagger$ & .262 \\
\hline Coronary fistula & .746 & .552 & .441 \\
\hline Major morbidity & - & $<.001 \dagger$ & $<.001 \dagger$ \\
\hline Mortality & $<.001 \dagger$ & - & .582 \\
\hline
\end{tabular}

